\title{
20q11.2 microdeletion syndrome
}

INSERM

\section{Source}

INSERM. (1999). Orphanet: an online rare disease and orphan drug data base. 20911.2 microdeletion syndrome. ORPHA:444051

20q11.2 microdeletion syndrome is a rare, genetic, syndromic intellectual disability characterized by psychomotor delay, hypotonia, feeding difficulties, failure to thrive, anomalies of the hands and feet (clinodactyly, camptodactyly, brachydactyly, feet malposition), and craniofacial dysmorphism. Associated prenatal growth retardation, and gastrointestinal, heart and eye anomalies have been reported. 